\title{
Management of severe traumatic brain injury: Evidence, tricks, and pitfalls
}

Editors: Terje Sundstrom, Per-Olof Grände, Niels Juul, Carsten Kock-Jensen, Bertil Romner, Knut Wester

Year: 2012

ISBN: 978-3-642-28125-9 (Print) 978-3-642-28126-6 (Online)

Binding: Hardcover

Publisher: Springer Berlin Heidelberg

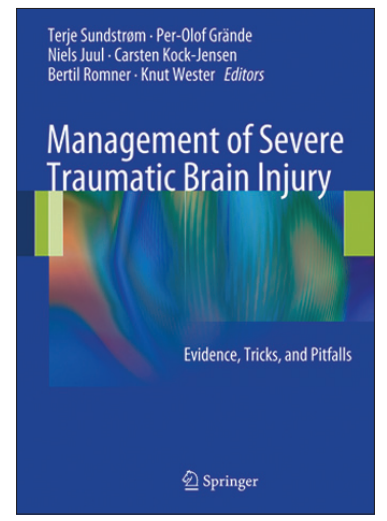

Traumatic brain injuries (TBI) particularly severe injuries are a leading cause of morbidity with far from satisfactory outcomes. Management of these patients is in the hands of experienced physicians and in critical and challenging circumstances. The book "Management of Severe Traumatic Brain Injury: Evidence, Tricks, and Pitfalls"[1] is an excellent attempt to provide exhaustive, yet comprehensive account for the management of patients with severe TBI. The presentation of the book in sections, that is, epidemiology, classification and assessment, prehospital management, admission, diagnostics and planning, acute surgical treatment, peroperative anesthesia, monitoring in neurointensive care, treatment in neurointensive care, early rehabilitation, outcome after severe TBI, and research in the neurointensive care unit represents hierarchy of approach for the management of severe traumatic brain injury patients. The book presents a unique collection of 72 topics in eight sections contributed by competent authorities in each field and covers almost all aspects necessary for the management of severe TBI ranging from epidemiology, prehospital care to follow up and rehabilitation. The present book, which emphasizes the need for practical approach to manage severe TBI, can be of great interest for many, including neurosurgeons, intensive care specialists, nurses, experts in the field of neuro-rehabilitation, and all who are involved in the management of such sick patients.
In summary, the important aspects and approaches in the management of severe TBI are well presented and supported by evidence-based recommendations for each diagnostic and therapeutic measure.

Amit Agarwal

Department of Neurosurgery, Narayana Medical College Hospital, Chinthareddypalem, Nellore, Andhra Pradesh, India

Address for correspondence: Dr. Amit Agrawal,

Department of Neurosurgery, Narayana Medical College Hospital, Chinthareddypalem, Nellore - 524 003, Andhra Pradesh, India. E-mail: dramitagrawal@gmail.com

\section{Reference}

1. Sundstrom T, Grände PO, Juul N, Kock-Jensen C, Wester K, Romner B. Management of severe traumatic brain injury: Evidence, tricks, and pitfalls. Springer: Berlin Heidelberg; 2012. p. 417.

\begin{tabular}{|l|l|}
\hline \multicolumn{2}{|c|}{ Access this article online } \\
\hline Quick Response Code: & \\
\hline & Website: \\
\hline & \\
\hline
\end{tabular}

